\title{
Provas de solidariedade africana nas tramas da História e da Literatura
}

\author{
Suillan Miguez Gonzalez ${ }^{1}$ \\ Mateus de Sá Barreto Barros ${ }^{2}$
}

RESUMO: Este artigo consiste na discussão acerca da solidariedade dos povos africanos, natureza essa comprovada a partir de um breve percurso histórico pelas sociedades africanas trazidas para a América. Tal solidariedade alcança, inclusive, o campo da literatura, mais propriamente das literaturas de língua portuguesa quando escritores moçambicanos e angolanos se propõem a escrever sobre a resistência no Timor-Leste em prol da conquista da liberdade de não ser o outro, e sim de firmar o ser timorense.

ABSTRACT: This paper is a discussion of solidarism African people, this proven nature from a brief history by African societies brought to America. Such solidarity reaches even the field of literature, more specifically the literatures in Portuguese when Mozambican and Angolan writers intend to write about the resistance in East Timor towards the achievement of freedom from the other, but to firm being Timorese.

PALAVRAS-CHAVE: Solidariedade; África; Literatura; Timor-Leste.

KEYWORDS: Solidarity; Africa; Literature; East Timor.

O presente artigo se propõe a percorrer as provas de solidariedade de povos africanos, a partir de um recorte específico da História, restringido aqui ao momento da escravidão a que foram submetidos já nos navios e depois na chegada à América, justamente pela condição do subjugado promover ligações de sensível irmandade e colaboração, de se ressignificarem culturalmente para resistirem.

Contemporaneamente, escritores angolanos e moçambicanos demonstraram no campo da literatura a solidariedade quando dedicaram obras ao Timor-Leste, ex-colônia portuguesa, que conta com apenas dez anos da restauração da independência. Antes disso, o país passou vinte e cinco anos sob o regime de massacre dos indonésios por não aceitar a anexação da ilha pela Indonésia, conflito em que se teve mais timorenses mortos do que o próprio holocausto.

Mia Couto, Teresa Amal e José Rodrigues dos Santos apresentaram e registraram como deles a causa e o direito pela resistência do povo timorense, historicizam, cada um a seu modo, quão o mundo permanece inerte ao sofrimento do

1 Mestre em Estudos Comparados de Literaturas de Língua Portuguesa pela Universidade de São Paulo. Projeto de doutorado: Timor onde as flores também desabrocham: a emergência de um cânone para a Literatura Timorense. E-mail: suillan2009@usp.br

2 Doutorando em Humanidades, Direitos e Outras Legitimidades pela Universidade de São Paulo. Cada grama de açúcar uma tonelada de injustiça: dilemas da política internacional brasileira de incentivo à produção de bioenergia. E-mail: masbbarros@usp.br 
outro. Eles, ao contrário, adotaram uma postura repulsiva a isso e escreveram o Timor, sobre o Timor, porque o seu povo merecia um Timor que deixasse de ser silenciado: "O silêncio pede a comparência da solidão. Mas os timorenses não estão sós: por isso não estão condenados ao silêncio" (GUSMÃO, 2003, p.8). Mia Couto traduz o ímpeto da solidariedade em que acredita, quando o próprio mundo vive em conflito: "Neste estilhaçar de tempo e mundo que lugar tem a solidariedade? Quanto nos pode ocupar a injustiça que ocorre distante quando, tantas vezes, fechamos os olhos àquela que tem lugar no nosso próprio lugar?” (GUSMÃO, 2003, p.6).

\section{A solidariedade no percurso histórico das sociedades africanas na América}

A solidariedade sempre foi uma marca presente nas sociedades africanas em solo americano, em que a sabida herança cultural vai além da feijoada, da capoeira ou de uma espiritualidade povoada por entidades, porque adentra o campo da coragem. As condições às quais foram submetidas possibilitaram, em grande medida, reconstruir seus roteiros históricos, mesmo sob a condição de oprimidos; as populações africanas e seus descendentes forjaram formas de resistência.

Para os antropólogos e historiadores é sempre muito complicado pensar no encontro entre África e América, pois, a África não é um continente que possui uma unidade étnica, cultural, linguística e religiosa; ao contrário, é um mundo múltiplo, complexo, como a própria América. Mintz e Price (2003) procuraram refazer esse encontro, da única forma possível, ensaisticamente, pensando que as populações africanas configurar-se-iam antes mesmo de subirem nos navios negreiros, em grandes aglomerados, sem uma língua possível de comunicação, sem um sistema religioso único e, mesmo, sem formas reconhecíveis de organização social. Seria, assim, o encontro de um mundo complexo, múltiplo, fragmentado, que forçosamente foi recriado na América.

Já nos navios, os africanos forjaram relações fortíssimas com seus parceiros de tormenta. Malungo, compadre ou companheiro, era o nome dado ao parceiro que dividia os momentos de sofrimento no navio, desde o início da viagem da África. Mintz e Price (2003) nos contam que essa denominação não é apenas um nome, mas um parentesco por associação que, por sua vez, era formado geralmente em pares durante o transatlântico. Esse laço era tão forte que a relação sexual entre eles poderia ser considerada pelo grupo como incestuosa. Os laços entre malungos poderiam ser 
duradouros, chegando a assumirem papéis religiosos muito importantes, como os de padrinhos e madrinhas, que manteriam o elo entre eles por toda a vida.

As relações de solidariedade, ainda no momento da viagem, permitiram aos africanos articularem organizações sociais complexas que iriam se fazer presentes nas suas formas de resistência em solo americano no período da escravidão. É fato que a maior parte das formas de resistência do negro escravizado se dava no cotidiano: a sabotagem de máquinas, o fingimento de doenças, a fuga pontual - na tentativa de negociar com seus senhores, para cobrar acordos que não foram firmados ou mesmo para visitar parentes em outras plantações. Isso significa que as revoltas e a formação de quilombos eram situações extremas, assim como o suicídio era o maior ato individual da negação da situação de escravizado. O interessante é que essas formas de resistência tinham uma intenção, qual seja: mostrar toda a humanidade dos negros aos seus senhores.

Mintz e Price defendem que os senhores reconheciam, de algum modo, a humanidade dos negros escravizados, uma vez que eram obrigados a lidar com eles diariamente. Com alguns ainda passavam juntos o dia todo, pois dialogavam sobre as atividades na plantação, distribuíam tarefas, pediam-lhes o relatório das atividades realizadas no dia, entre outros. Nesse caminho, o repúdio ao reconhecimento, por certo, era demasiadamente contraditório. Tal contradição se dá quanto aos filhos dos senhores passarem a maior parte do tempo com suas amas de leite e com os negros escravizados, os quais, por seu turno, realizavam trabalhos domésticos. Além disso, obviamente, os senhores se alimentavam de acordo com a decisão da cozinheira, igualmente escrava. Esta, por sua vez, escolhia a alimentação segundo o seu calendário religioso e as exigências das deidades. Não é por acaso que os pratos típicos da região caribenha e nordestina são de origem afro-americana.

O mundo colonial já trazia inerente à sua configuração a complexidade, inclusive quanto à formação de diversas classes sociais. Mesmo a classe escrava era subdividida em muitas outras, uma vez que havia, para a sociedade maior, uma diferença clara entre escravos africanos e crioulos - já nascidos na América - e entre esses uma distinção entre os mais claros e os mais escuros. No entanto, esses fatores não retiravam a possibilidade de laços de solidariedade, de acordo com os interesses entre as classes escravas. É à luz de tais interesses que Mintz (2003) traz à baila a subordinação de uma negra escrava jamaicana. Tal subordinação, por seu turno, era utilizada como estratégia para que ela ocupasse o cargo de cozinheira e, consequentemente, pudesse colocar vidro moído na refeição de seu senhor. O autor reitera que isso era 
completamente possível, porque o trabalho exaustivo, somado à repressão cotidiana, transformava a vida dos africanos em um cenário deplorável.

Carvalho (1998), por sua vez, corrobora tal assertiva quando afirma que eram vários os acontecimentos na história das Américas sobre revoltas que foram lideradas por ex-feitores e outros escravos que conseguiam a confiança dos patrões, ocupando, desse modo, os mais altos cargos para um cativo, obviamente. Quem viesse ocupar esses cargos teria um maior contato com seus patrões e conheceria sua rotina, o que facilitava os momentos mais radicais. $\mathrm{O}$ autor chama a atenção ainda para o fato de que eram os próprios escravos que escolhiam aqueles que ocupariam tais cargos. Pois os escolhidos deveriam ser "[...] bons administradores de brancos, negros espertíssimos, que sabiam quando e quanto ceder ou resistir" (1998, p.209); muito embora fossem os mestiços a experimentar com frequência a face paternalista da escravidão. De algum modo, isso lhes permitia conhecer e explorar mais habilmente as fraquezas de seus senhores no cotidiano.

Na cidade, a solidariedade se fazia presente, à sua própria maneira, incorporando novas etnias. O levante dos Malês (REIS e SILVA, 1989) em Salvador, Bahia, foi uma outra rebelião escrava que ocorreu no centro urbano. Os Malês utilizaram as brechas que podiam encontrar no sistema escravista para planejarem suas ações, e o espaço urbano possibilitava, de certa maneira, essa articulação, apesar dos instrumentos e instituições opressoras muito presentes. Os negros escravizados ou livres dividiam apartamentos, promoviam seus cantos e cultivavam seus deuses nesses espaços. Além disso, planejavam suas ações, visto que as práticas dos negros escravizados “[...] funcionaram como rituais de reafirmação de suas diferenças étnicas, mas também como rituais de rebelião. Outras vezes" - diz ainda Reis - “[...] elas foram antecipações de verdadeiros levantes, que terminaram por envolver diversos grupos étnicos africanos contra os brancos" (REIS e SILVA, 1989, p.101).

Uma questão importante, talvez, seria considerar o caráter político dos escravos islamizados. Primeiramente, os aspectos religiosos, em amplo sentido, foram recriados, tanto com materiais africanos quanto com americanos. O mais importante, nessa perspectiva, foi o fato de os Malês não terem trazido as escrituras sagradas, o que fez com que, na Bahia, a religião islâmica não fosse, em sentido algum, fundamentalista (REIS, 1988). Contudo, não significa dizer que não havia questões características da religião. 
Os rebeldes modernos agem nos dias de trabalho, os escravos agiam no de folga. Em 1835 esse dia foi o domingo da festa de Nossa Senhora da Guia... De acordo com o calendário islâmico, os malês estavam festejando o fim do Ramadã, a festa do Lailat al-Qadr (Noite do Poder). O mês sagrado do Ramadã traz para os adeptos de Maomé uma força espiritual especial e, na Noite do Poder, Alá controla os espíritos malignos e reordena os negócios do mundo... Eles procuraram manipular pelo menos três campos do poder ao mesmo tempo [...] O poder do Estado escravocrata estava debilitado pelas divisões entre os homens livres; o poder dos senhores relaxado pelo domingo de festa; e o poder do deus do homem branco sob a mira de Alá. A política rebelde tinha sua lógica própria. (REIS e SILVA, 1989, p. 122)

A forma como foi articulada a solidariedade pelos Malês, negociando, quando possível a permanência de seus repertórios históricos, a partir do que se lembravam, demonstra o quão políticos eram os africanos. E para apreendermos as marcas da solidariedade africana é necessário realizarmos minimamente a remissão de um passado que repercute o nosso presente, para que se compreenda o princípio do forjar desses laços e como eles se desenrolam em âmbitos outros.

Utilizaram e utilizam provas das mais diversas para firmar o vínculo de solidariedade, ainda mais se é algo inerente a povos, principalmente na adversidade, como é o caso dos africanos. A rede de comunicação cultural atual pode se dar pelo sistema literário, aliás, entre sistemas literários. A discussão quanto à solidariedade comprova a manifestação de moçambicanos e angolanos quanto a sociedades que sofrem, em tempos recentes, bem como os africanos também sofreram, tanto na América como na própria África com a colonização.

O mundo ainda apresenta uma série de conflitos estabelecidos por discordâncias quanto à pertença de território ou mesmo pelo fato de nações invadirem outras. Os somente dez anos de independência de Timor-Leste são um exemplo disso, sendo a Indonésia a invasora e a desencadeadora de vinte e cinco anos de imposição linguística e cultural. A violência deste processo foi divulgada e mesmo presenciada por alguns dos literatos de países africanos de língua portuguesa, como a escritora Teresa Amal. Ela e outros escritores procuraram legitimar esse país por intermédio da literatura, porque produziram relatos, prefácios, romances, crônicas em que puderam demonstrar a existência de um lugar em que pessoas estavam sendo impedidas de viver e praticar livremente a própria cultura.

\section{A solidariedade na literatura: as obras africanas sobre o Timor}


No compasso da utopia libertária proposta por Benjamin Abdala Junior no conjunto de ensaios e artigos reunidos no livro De Vôos e Ilhas: Literatura $e$ Comunitarismos, há a discussão de que tanto o processo histórico-cultural quanto o social envolvem momentos de ascensão e queda, sendo que o estudioso elege a imagem mítica de Ícaro para tecer suas conjecturas acerca dos gestos libertários. Ao se pensar nas Literaturas de Língua Portuguesa, mais propriamente nas ex-colônias portuguesas que experenciaram diferentes relações com o colonizador e, a partir daí, concretizaram uma condição mestiça e um repertório cultural próprios, estas se solidarizaram e hoje compõem não só a Comunidade de Países de Língua Portuguesa - CPLP, mas um senso de coletividade em prol da estandartização da literatura produzida sob a marca consciente de crioula, mesmo em alguns casos, com o do Timor-Leste, ainda em processo de formação no que diz respeito à produção de obras em língua portuguesa.

Ao que parece, as fronteiras da solidariedade - principalmente dos países africanos lusófonos - ultrapassaram continentes e mesmo uma divisão de mundo imaginária, mas essencialmente ideológica: a possibilidade de o Ocidente dialogar culturalmente com o Oriente. O poder da solidariedade na literatura se revelou inclusive intervencionalista e divulgador de violações dos direitos humanos no Timor-Leste, comprovando a função mais lírica e instigante da literatura: lembrar-nos da nossa humanidade. Neste ensejo, têm-se escritores africanos de Moçambique e de Angola publicando obras sobre o Timor, ou ainda, legitimando as poucas obras lançadas pelos timorenses, no sentido de promover o direito não somente à restauração da independência deste país, mas à liberdade de reaver a singularidade de um povo no território em que ele se constituiu.

Mia Couto prefaciou o livro de poesias e pinturas Mar Meu, do líder da guerrilha timorense, Xanana Gusmão. O escritor moçambicano se mostra partidário e porta-voz da causa timorense, apresentando como imagem da solidariedade um passado em comum, marcado ideologicamente no discurso como nosso:

Timor parece erguer-se como prova contrária a estes sinais de decadência. Afinal, há alma para sustentar causas, erguer a voz, recusar alheamentos. Uma nação distante se reassume como nosso lar; nossa razão, nosso empenho. O sangue que se perde em Timor escorre de nossas próprias veias. As vidas que se perdem em Timor pesam sobre a nossa própria vida. (GUSMÃO, 2003, p.6) 
Teresa Amal, angolana, dedicou duas obras ao Timor, Timor Leste: Crónica da Observação da Coragem e Sete mulheres de Timor, com o intuito de evidenciar a característica mais marcante da identidade timorense: a resistência, palavra da Língua Portuguesa, no entanto, ressignificada em território timorense, onde a língua do colonizador foi apagada pelos indonésios. A resistência leste-timorense se constituiu em aguentar, em sobreviver, em se privar, em se deslocar para as montanhas, em chorar silenciosamente os mortos, em esperar pacientemente o momento do despertar da solidariedade da comunidade internacional de países, para que percebessem o dilaceramento de um povo certo de que apenas o sentido da liberdade e democracia lhe atenderia. A literatura, nesta perspectiva, vai além do reconhecimento de um direito político, abraça a urgência de uma nação e a aprisiona para revelá-la ao mundo.

Em Crónica da Observação da Coragem, Amal, por meio do relato da vivência no coração da tragédia, testemunhou e registrou a luta e a esperança de um povo feito de rostos, vozes, cheiros e sons concretos, a cores:

Poderá parecer uma repetição inútil e até talvez maçadora a que faço da beleza da ilha de Timor e da coragem do seu Povo. Talvez me falte o génio para encontrar outras coisas e outras formas de o dizer mas se me ativer ao poder do que vi e com o que vi o que senti, não posso deixar de repetir mil vezes as mesmas coisas porque de tudo isso foi feita esta observação da coragem, até da natureza, de resistir sempre e sempre majestosamente a tantas punições injustas e incompreensíveis. (AMAL, 2002, p.11).

Enveredado pela mesma linha da necessidade de historicização das " verdades" sobre os conflitos vividos pelo Timor, o moçambicano José Rodrigues dos Santos, naturalizado português, profissional premiado na área da Comunicação Social e que investigou profundamente os detalhes da tentativa do povo leste-timorense de autonomia absoluta do país, elaborou o que foi chamado pela crítica de Ficção/Verdade, ou seja, contar "as verdades" através da ficção, neste caso: a ficcionalização da transição de um momento político tenso até a efetiva invasão dos soldados indonésios a partir da liderança do ditador Suharto.

A obra Ilha das Trevas denuncia as atrocidades dos invasores, o planejamento indonésio em prol da aniquilação completa de um povo para anexar a ilha ao conjunto de milhares de outras pertencentes à Indonésia, e aponta a guerrilha como o único subterfúgio político e estratégico para não permitirem o subjugo.

O romance conta com uma personagem, Paulino da Conceição, relutante quanto às suas memórias da história sangrenta vivenciada, passa as noites em claro, numa 
insônia de guardar um segredo. Paulino teve que cometer um crime: um assassinato para defender a família da morte; nem mesmo num contexto extremo de guerra declarada há a absolvição de um gesto como este, a pacificidade e a religiosidade da cultura de que faz parte o colocam na certeza de que fez o mal, de que o mal estava ali estabelecido e havia ele cedido a isso.

A narrativa histórica finaliza num tom de recuperação de fôlego, de um alívio desesperado em registrar a retomada e respeito da dignidade dos timorenses; todavia, as milhares de vidas perdidas permanecem como uma memória que transcende o solo timorense e se torna a saudade infinita da singularidade do ser, do nosso ser:

De pé na bancada e de olhos cerrados, Paulino encheu os pulmões com o ar puro daquela brisa de liberdade, sentiu no vento os fantasmas dos filhos a afastarem-se para o mar, seria sugestão, seria nostalgia, seria ilusão, seria a dor que agora vai e que mais tarde vem, ou será que já não vem?, seria a ânsia e o desespero de acreditar num perdão, seria a doce fantasia da esperança, seriam saudades de Esmeralda, ou seria simplesmente o orgulho, aquele orgulho de quem tudo perdera, tudo mesmo, e algo enfim recuperara.

A dignidade.

Timor-Leste abandonara finalmente as trevas, mas quão difícil e tormentoso tinha sido o longo caminho para Tacitolo. (SANTOS, 2011, p. 351-352)

As obras e escritores africanos supramencionados não somente são colaboradores de uma rede de denúncias, mas cumprem o papel de garantir à literatura emergente do Timor o impulso para a formação de um sistema literário em Língua Portuguesa. A solidariedade na literatura envolvendo africanos e timorenses é firmada por um histórico de lutas com as quais esses povos lidaram ou ainda lidam, porque a resistência tornou-se um destino escolhido para ambos.

\section{Referências bibliográficas}

ABDALA, Benjamin Junior. De Vôos e Ilhas: Literatura e Comunitarismos. Cotia: Ateliê Editorial, 2003.

AMAL, Teresa. Timor Leste: Crónica da Observação da Coragem. Coimbra: Quarteto, 2002.

Sete Mulheres de Timor. Coimbra: Quarteto, 2001.

CARVALHO, Marcos J.M. de. Liberdade: Rotinas e Rupturas do Escravismo. Recife, 1822-1850. Recife: Editora Universitária (UFPE), 1998.

GUSMÃO, Xanana. Mar meu. Lisboa: Instituto Camões, 2003. 
MINTZ, Sidney Wilfred; PRICE, Richard. O Nascimento da Cultura Afro-Americana: Uma Perspectiva Antropológica. Rio de Janeiro: Pallas: UCAM, 2003.

MINTZ, Sidney W. Era o Escravo de Plantação um Proletário? In: O Poder Amargo do Açúcar. Produtores escravizados, consumidores proletarizados. Organização e tradução de Christine Rufino Dabat. Recife: Editora Universitária da UFPE, 2003.

MOTT, Luiz R. B. Terror na Casa da Torre: tortura de escravos na Bahia colonial. In: João José Reis (Org.). Escravidão e Invenção da Liberdade: Estudos sobre o negro no Brasil. São Paulo: Brasiliense, 1988.

REIS, João José; SILVA, Eduardo. Negociação e Conflito: A Resistência Negra no Brasil Escravista. São Paulo: Companhia das Letras, 1989.

REIS, João José. Um Balanço sobre as Revoltas escravas da Bahia. In. João José Reis (Org.). Escravidão e Invenção da Liberdade: Estudos sobre o Negro no Brasil. São Paulo: Brasiliense, 1988.

SANTOS, José Rodrigues dos. A Ilha das Trevas. Libia: Gradiva, 2011. 